\title{
Vertical and Horizontal Intra Industry Trade in Some Asian and Latin American Less Developed Countries
}

\author{
Ranajoy Bhattacharyya \\ Calcutta University
}

\begin{abstract}
A casual look at the intra industry trade (IIT) data of eighteen Asian and Latin American less developed countries show that for them (a) vertical IIT overwhelmingly dominates horizontal IIT and (b) manufactured goods (SITC 6) is one of the two commodity categories (the other being machine and transport equipments (SITC 7)) for which IIT is relatively high. A theoretical model consistent which these observation is constructed and suggests the hypothesis that the level of economic development is a determining character for such kind of trade. Returning to the raw data set we find that such a relationship can indeed be established. Though the overall relationship clearly holds, there are major fluctuations with in the sample and the overall growth rate of IIT falls with increasing levels of economic development.
\end{abstract}

- JEL Classifications: F1

- Key Words: intra industry trade, vertical product differentiation

\section{Introduction}

The aim of this paper is to highlight two rather neglected areas in the empirical literature on intra-industry trade (IIT).First, the paper targets the less developed countries (LDCs) for a comprehensive analysis of their IIT. Secondly, it clearly distinguishes between IIT in vertically and horizontally differentiated products and singles out the former for a theoretical as well as empirical analysis in the context of the LDCs. This is done primarily because, of the two types of IIT, vertical IIT

\footnotetext{
*Corresponding address: Ranajoy Bhattacharyya, Department of Business Management, Clacutta University, 1 Reformatory Street, Calcutta 700027, India. E-mail:branajoy@ hotmail.com ()2002-Center for International Economics, Sejong Institution, All Rights Reserved.
} 
is seen to dominate horizontal IIT for the countries in the sample.

The need for the distinction between the two types of IIT arises from the fact that they require different types of theoretical structure for their analysis. Standard papers on IIT use models on horizontal IIT in developed countries (DCs) as the theoretical backdrop for testing hypotheses on IIT which are of the mixed (horizontal as well as vertical) variety ${ }^{1}$. The result is that many important determinants of IIT latent in the chosen theoretical structure do not find empirical support. As an example we can consider one of the most important variables considered by the traditional IIT models (see Helpman (1987) for a survey), viz, economies of scale. Loerstcher and Wolter (1980), Caves (1981) and Finger and De Rosa (1979) found negative signs for the economies of scale variable in their regression thus proving that, contrary to the wisdom of the models, the variable does not affect IIT positively. In a comparatively recent paper Trotsenson (1996) tested the robustness of the variables suggested by the traditional models for Sweden (arguably the most studied country in the world as far as determinants of IIT are concerned) and found that most of them (including economies of scale) failed the effective bounds analysis (EBA) devised by Leamer. There are numerous other examples (see Leamer and Levinson (1995) for some other cases) of the traditional variables not finding support in empirical exercises. One of the major reasons for the failures is that IIT can be generated by a host of economic structures all of which do not embrace the variables suggested by the theories that were well known initially. Falvey and Kierkowski (1987), Flam and Helpman (1989) and more recently Davis (1997)have suggested alternative scenarios for IIT that do not require increasing returns to scale to explain it. As Jones et al. (1998) point out, certain varieties of IIT can easily be accommodated into the traditional Heckscher-Ohlin framework of international trade by using the concept of factor endowments more broadly than what is implied in the original theory.If these authorrs are right then it is not unusual to find 'economies of scale' to be a redundant variable in explaining IIT.

It is therefore necessary to take a more careful look at the IIT data of different countries before we can form our opinion regarding the appropriate structure to be used in modeling IIT of these countries. In this paper we first take a casual look at the IIT figures of thirteen LDCs and then suggest a theoretical model on IIT based on the observations thus made. The model is used to derive a simple proposition regarding IIT of this variety. The proposition is then tested in the form

\footnotetext{
${ }^{1}$ See Leamer and Levinson (1995)for a critical survey.
} 
of a hypothesis with the data of the thirteen countries that we have.

The classification of IIT into vertical and horizontal components was first accomplished by Greenaway et al. (1994,1995). The methodology they follow is the following: IIT is horizontal if unit value of export relative to import is within $15 \%$. If the unit value of export relative to import is greater than $15 \%$ then IIT is classified as vertical. We have followed this methodology in this paper. All industries where trade occurs is first classified into ones which take part in horizontal trade and vertical trade by using the above criteria. Since the criteria compares unit values of import and export, obviously all industries for which either import or export is zero has to be first eliminated ${ }^{2}$. After the classification is made, average IIT is calculated over all the industries in the particular category.

The standard index used for calculating IIT for a group of industries is the Grubel-Lloyd (uncorrected)index first suggested by Grubel and Lloyd(1975). The index is defined as follows:

$$
I_{G L(U)}=1-\frac{\sum\left|X_{i}-M_{i}\right|}{\sum\left(X_{i}-M_{i}\right)}
$$

Where the summation runs over industries. Given the nature of the data here and our objective of dividing IIT into two different categories, we need to slightly modify the index for our purpose. Note that given our objective, (1) we have to first eliminate all zero IIT industries and (2) the division of industries into vertical and horizontal components leaves an unequal number of industries in each group. The former problem leads to the elimination of a large number of industries, leaving very few in each category, especially in the horizontal IIT category ${ }^{3}$. If these industries happen to have a high IIT then the average IIT calculated from them is correspondingly high ${ }^{4}$, irrespective of whether these industries account for a very large or very small proportion of total trade. The second fact aggravates this problem by over (under) reporting the value of the index for either the vertical or horizontal category. To take care of this problem we have modified $G L(U)$ as follows:

\footnotetext{
${ }^{2}$ This has important implications as far as the magnitude of average IIT over all industries is concerned. The elimination of zero export(or import) industries and hence all industries with zero IIT gives the IIT figures calculated an upward bias.

${ }^{3}$ Because very few industries have horizontal trade in LDCs.

${ }^{4}$ Thus, for example, if for a certain country, there is only one industry in the horizontal category with positive IIT, and if IIT for it is .95 but there are ten industries in the vertical category with highest IIT .98 but lowest IIT .02 then average IIT calculated by using $G L(U)$ is obviously much lower for the vertical component than for the horizontal component.
} 


$$
\begin{gathered}
N I I T_{V E R}=\left[\frac{M_{V E R}+X_{V E R}}{M_{T O T}+X_{T O T}}\right] \times G L(U)_{V E R} \\
N I I T_{H O R}=\left[\frac{M_{H O R}+X_{H O R}}{M_{T O T}+X_{T O T}}\right] \times G L(U)_{H O R}
\end{gathered}
$$

where $M_{V E R}\left(M_{H O R}\right)$ and $X_{V E R}\left(X_{H O R}\right)$ are the total import and export of all nonzero $I I T$ industries falling in the vertical (horizontal) category. $M_{T O T}$ and $X_{T O T}$ are defined as:

$$
\begin{gathered}
M_{T O T}=M_{V E R}+M_{H O R} \\
X_{T O T}=X_{V E R}+X_{H O R}
\end{gathered}
$$

and $\operatorname{NIIT}_{V E R}\left(N I I T_{H O R}\right)$ is the new IIT index for the vertical (horizontal) category.

These indices have the attribute that their value increases (decreases) as the proportion of trade accounted for by the particular category (vertical and horizontal)increases(decreases). The index is thus a better indicator of the actual importance of IIT within a particular category of trade.

Though the above indices serve our purpose better we none the less sometimes report the $G L(U)$ index alongside the above indices for purposes of comparison.

Given the above objectives and the methodology of the work, we divide the rest of the paper into the following sections: section 2 presents the basic data regarding the thirteen LDCs and chooses an appropriate model on IIT in LDCs. Section 3 presents an international duopoly model on vertical IIT in between LDCs and DCs and derives a simple proposition regarding the positive relationship between vertical IIT and the level of economic development. Sections 4 and 5 test this proposition in the form of a hypothesis by using the data on the thirteen LDCs. While section 4 tests the hypothesis directly, section 5 determines the growth rate of vertical IIT with respect to GNP and GDP and compares it to the growth rate of total trade volume. Section 6 concludes the paper.

\section{Vertical And Horizontal IIT In LDCs: The Data}

Table 1 reports the break up of IIT between vertical and horizontal components in the sample countries. First and foremost, it is clear from the table that (1) the division of industries into vertical and horizontal components is extremely unequal and hence (2) the new index gives us a more reliable estimate of the actual 
Table 1. Breakup of IIT between vertical and horizontal components in the sample countries (3 digit SITC, 15\% level)

\begin{tabular}{|c|c|c|c|c|c|c|c|c|c|c|c|c|}
\hline \multirow{3}{*}{ Country } & \multicolumn{4}{|c|}{1990} & \multicolumn{4}{|c|}{1991} & \multicolumn{4}{|c|}{1992} \\
\hline & \multicolumn{2}{|c|}{$G L(\mathrm{U})^{1}$} & \multicolumn{2}{|c|}{$N_{I I T}{ }^{2}$} & \multicolumn{2}{|c|}{$G L(U)^{1}$} & \multicolumn{2}{|c|}{$N I I T^{2}$} & \multicolumn{2}{|c|}{$\mathrm{GL}(\mathrm{U})^{1}$} & \multicolumn{2}{|c|}{$\mathrm{NIIT}^{2}$} \\
\hline & VER & HOR & VER & HOR & VER & HOR & VER & HOR & VER & HOR & VER & HOR \\
\hline \multicolumn{13}{|c|}{ Lower and lower middle income countries } \\
\hline INDIA & $0.68(5)$ & $0(0)$ & 0.03 & 0 & $0.74(4)$ & $0.88(1)$ & 0.03 & 0.007 & $0.58(7)$ & $0.858(1)$ & 0.04 & 0.006 \\
\hline PAKISTAN & $0.19(3)$ & $0(0)$ & 0.03 & 0 & $0.18(3)$ & $0(0)$ & 0.03 & 0 & $0.27(2)$ & $0(0)$ & .009 & 0 \\
\hline INDONESIA & $0.65(6)$ & $0.382(5)$ & 0.05 & 0.003 & $0.53(13)$ & $0.52(4)$ & 0.08 & 0.040 & $0.54(11)$ & $0.587(5)$ & 0.10 & 0.030 \\
\hline $\begin{array}{l}\text { PHILIP- } \\
\text { PINES }\end{array}$ & $0.45(8)$ & $0.596(1)$ & 0.07 & 0.008 & $0.66(12)$ & $0.93(1)$ & 0.14 & 0.210 & $0.67(14)$ & $0.190(1)$ & 0.25 & 0.003 \\
\hline COLUMBIA & $0.59(8)$ & $0.374(2)$ & 0.08 & 0.006 & $0.69(9)$ & $0(0)$ & 0.10 & 0 & $0.75(5)$ & $0.461(2)$ & 0.06 & 0.040 \\
\hline THAILAND & 0.67 (9) & $0.347(1)$ & 0.10 & 0.007 & $0.67(8)$ & $0(0)$ & 0.09 & 0 & $.79(7)$ & $0(0)$ & 0.10 & 0 \\
\hline CHILE & $0.62(3)$ & $0(0)$ & 0.02 & 0 & $0.74(5)$ & $0(0)$ & 0.04 & 0 & $0.45(7)$ & $0.846(1)$ & 0.05 & 0.006 \\
\hline Mean & 0.55 & 0.24 & 0.05 & 0.003 & 0.60 & 0.33 & 0.07 & 0.04 & 0.58 & 0.42 & 0.09 & 0.01 \\
\hline $\mathbf{C V}^{4}$ & 29.75 & 92.00 & 51.03 & 95.92 & 30.60 & 120.9 & 52.76 & 196.18 & 28.90 & 80.90 & 83.90 & 122.5 \\
\hline \multicolumn{13}{|c|}{ Upper middle and high income LDCs } \\
\hline ARGENTINA & $0.52(24)$ & $0.848(4)$ & 0.28 & 0.07 & $0.59(24)$ & $0.450(2)$ & 0.29 & 0.01 & $0.38(20)$ & $0.529(5)$ & 0.12 & 0.064 \\
\hline URUGUAY & $0.39(16)$ & $0.600(5)$ & 0.17 & 0.06 & $0.40(14)$ & $0.609(6)$ & 0.13 & 0.11 & $0.45(16)$ & $0.686(4)$ & 0.16 & 0.035 \\
\hline BRAZIL & $0.50(28)$ & $0.563(2)$ & 0.23 & 0.03 & $0.57(32)$ & $0.528(1)$ & 0.32 & 0.01 & $0.53(32)$ & $0.964(1)$ & 0.28 & 0.014 \\
\hline KOREA & $0.60(5)$ & $0.562(1)$ & 0.83 & 0.15 & $0.64(8)$ & $0.598(1)$ & 0.70 & 0.05 & $0.69(8)$ & $0.535(2)$ & 0.90 & 0.122 \\
\hline SINGAPORE & $0.74(9)$ & $0.76(3)$ & 0.68 & 0.07 & $0.57(12)$ & $0.860(2)$ & 0.50 & 0.10 & $0.54(11)$ & $0.786(2)$ & 0.48 & 0.084 \\
\hline $\begin{array}{l}\text { HONG } \\
\text { KONG }\end{array}$ & $0.68(9)$ & $0.813(8)$ & 0.43 & 0.30 & $0.71(12)$ & $0.829(7)$ & 0.45 & 0.30 & $0.78(8)$ & $0.841(7)$ & 0.48 & 0.326 \\
\hline Mean & 0.57 & 0.69 & 0.44 & 0.11 & 0.58 & 0.64 & 0.40 & 0.097 & 0.56 & 0.72 & 0.40 & 0.11 \\
\hline $\mathrm{CV}$ & 2041 & 17.37 & 55.50 & 82.07 & 16.23 & 23.26 & 45.10 & 103.30 & 24.20 & 21.88 & 65.06 & 96.37 \\
\hline
\end{tabular}

Notes: 1. The Grubel- lloyd (uncorrected) index (see text for definition) 2. See text for definition. 3. Figures in brackets are the number of industries in each category, 4. Coefficient of variation.

Source: Calculated from The International Trade Statistics Yearbook (various issues). 
Table 2. Vertical IIT in the Sample Countries Arranged According to Their Mean Values Over 1990-1992 New index ${ }^{1}$, (SITC 3 digit 15\%)

\begin{tabular}{|llll|}
\hline Country & NIIT & Country & NIIT \\
\hline KOREA & 0.81 & THAILAND & 0.10 \\
SINGAPORE & 0.55 & COLUMBIA & 0.08 \\
HONGKONG & 0.45 & INDONESIA & 0.08 \\
BRAZIL & 0.28 & CHILE & 0.04 \\
ARGENTINA & 0.23 & INDIA & 0.03 \\
URUGUAY & 0.15 & PAKISTAN & 0.02 \\
PHILIPPINES & 0.15 & & \\
\hline
\end{tabular}

Notes 1: See text for definition.

Source: Calculated from The International Trade Statistics Yearbook, (various issues).

Table 3. Responsiveness of Vertical IIT to Differences in Classification Level.(average 1990 to 1992 , New index $)^{1}$

\begin{tabular}{|lccc|}
\hline Country & 3 DIGIT & 4 DIGIT & 5 DIGIT \\
\hline INDIA & 0.033 & 0.013 & 0 \\
PAKISTAN & 0.023 & 0.010 & 0 \\
INDONESIA & 0.077 & 0.023 & 0.041 \\
PHILIPPINES & 0.153 & 0.113 & 0.032 \\
COLUMBIA & 0.080 & 0.023 & 0.023 \\
THAILAND & 0.097 & 0.147 & 0.055 \\
CHILE & 0.037 & 0.010 & 0 \\
ARGENTINA & 0.230 & 0.173 & 0.016 \\
URUGUAY & 0.153 & 0.567 & 0.124 \\
BRAZIL & 0.277 & 0.150 & 0.018 \\
KOREA & 0.810 & 0.117 & 0.015 \\
SINGAPORE & 0.553 & 0.167 & 0.158 \\
HONG KONG & 0.453 & 0.183 & 0.173 \\
\hline
\end{tabular}

Notes: 1 See text for definition.

Source: Calculated from The International Trade Statistics Yearbook, (various issues).

importance of IIT in the sample countries. Going therefore, by the new index it is clear that vertical IIT (VIIT) dominates horizontal IIT (HIIT) for the sample countries and over the sample period so much, so that average VIIT is well higher than average HIIT (.23 vs .06). The gap also clearly increases with the level of economic development of the countries. The proportion of VIIT in total trade also rises with the level of income of the countries (Table 2). Finally, though VIIT falls with disaggregation of SITC categories it does not tend to vanish except when the initial level of IIT at the broadest classification level (SITC 3 digit level) is very small (Table 3). 
Table 4. Responsiveness of Vertical and Horizontal NIIT to Differance in Import Price and Export Price (average of 1990 to 1992, 3 digit )

\begin{tabular}{|lrrrrrrrr|}
\hline \multirow{2}{*}{ Country } & \multicolumn{2}{c}{$15 \%$} & \multicolumn{2}{c}{$25 \%$} & \multicolumn{2}{c}{$40 \%$} & \multicolumn{2}{c|}{$50 \%$} \\
\cline { 2 - 8 } & \multicolumn{1}{c}{ Ver } & \multicolumn{1}{l}{ Hor } & \multicolumn{1}{c}{ Ver } & \multicolumn{1}{c}{ Hor } & \multicolumn{1}{c|}{ Ver } & \multicolumn{1}{c}{ Hor } & \multicolumn{1}{c|}{ Ver } & \multicolumn{1}{c|}{ Hor } \\
\hline INDIA & $.031(16)$ & $.004(2)$ & $.029(15)$ & $.006(3)$ & $.028(14)$ & $.008(4)$ & $.023(11)$ & $.013(7)$ \\
PAKISTAN & $.024(8)$ & $0(0)$ & $.243(8)$ & $0(0)$ & $.009(6)$ & $.016(2)$ & $.009(6)$ & $.016(2)$ \\
INDONESIA & $.076(30)$ & $.034(14)$ & $.061(25)$ & $.050(19)$ & $.051(20)$ & $.059(24)$ & $.044(17)$ & $.066(27)$ \\
PHILIPPINES & $.151(34)$ & $.074(5)$ & $.125(29)$ & $.101(10)$ & $.064(22)$ & $.161(17)$ & $.043(21)$ & $.162(18)$ \\
COLUMBIA & $.080(22)$ & $.015(6)$ & $.078(21)$ & $.017(7)$ & $.029(13)$ & $.066(15)$ & $.025(11)$ & $.070(17)$ \\
THAILAND & $.098(24)$ & $.002(1)$ & $.070(18)$ & $.030(7)$ & $.044(12)$ & $.057(13)$ & $.039(10)$ & $.062(15)$ \\
CHILE & $.030(15)$ & $.002(1)$ & $.023(9)$ & $.015(7)$ & $.018(8)$ & $.020(8)$ & $.018(8)$ & $.020(8)$ \\
ARGENTINA & $.227(68)$ & $.047(11)$ & $.185(56)$ & $.059(23)$ & $.124(37)$ & $.150(42)$ & $.087(27)$ & $.187(52)$ \\
URUGUAY & $.155(46)$ & $.065(15)$ & $.140(38)$ & $.078(22)$ & $.095(26)$ & $.122(35)$ & $.085(22)$ & $.132(39)$ \\
BRAZIL & $.277(92)$ & $.018(4)$ & $.264(87)$ & $.031(9)$ & $.231(77)$ & $.062(19)$ & $.178(60)$ & $.118(36)$ \\
KOREA & $.810(21)$ & $.109(4)$ & $.481(18)$ & $.149(7)$ & $.383(12)$ & $.291(13)$ & $.249(9)$ & $.381(16)$ \\
SINGAPORE & $.554(32)$ & $.085(7)$ & $.415(25)$ & $.224(14)$ & $.315(17)$ & $.323(22)$ & $.253(14)$ & $.385(25)$ \\
HONGKONG & $.454(29)$ & $.310(22)$ & $.298(20)$ & $.465(31)$ & $.226(14)$ & $.538(37)$ & $.205(12)$ & $.559(39)$ \\
\hline
\end{tabular}

Source: Calculated from The International Trade Statistics Yearbook, (various issues).

Table 5. Breakup of Industries with Vertical $I I T$ into $P_{M}>P_{X}$ and $P_{M}<P_{X}$ Categories (3 digit, 1990 to 1992 total, $15 \%$ level)

\begin{tabular}{|lccc|}
\hline Country & $P_{M}>P_{X}$ & $P_{M}<P_{X}$ & Total \\
\hline INDIA & 9 & 7 & 16 \\
PAKISTAN & 5 & 3 & 8 \\
INDONESIA & 22 & 8 & 30 \\
PHILIPPINES & 15 & 19 & 34 \\
COLUMBIA & 13 & 9 & 22 \\
THAILAND & 17 & 7 & 24 \\
CHILE & 11 & 4 & 15 \\
ARGENTINA & 46 & 21 & 67 \\
URUGUAY & 13 & 33 & 46 \\
BRAZIL & 75 & 17 & 92 \\
KOREA & 11 & 10 & 21 \\
SINGAPORE & 15 & 17 & 32 \\
HONGKONG & 7 & 22 & 29 \\
\hline
\end{tabular}

Source: Calculated from The International Trade Statistics Yearbook, (various issues).

Table 4 and 5 bring out two important characteristic of VIIT. First, though the level of VIIT falls and HIIT rises as we increase the dispersion between import and export unit value it does not tend to vanish. This implies that a large number of industries categorised within VIIT have a large amount of difference between their import and export values (Table 4). Further, for most countries in the sample the import unit value is higher than export unit value implying that the countries tend 
Table 6. Breakup of Vertical IIT in the Sample Countries at the Industry Level

\begin{tabular}{|crrrrrrrrrrrrr|}
\hline $\begin{array}{c}\text { Aggregation } \\
\text { level }\end{array}$ & \multicolumn{3}{c}{ SITC5 } & \multicolumn{3}{c}{ SITC6 } & \multicolumn{3}{c|}{ SITC7 } & \multicolumn{3}{c|}{ SITC8 } \\
\cline { 2 - 3 } & 1990 & 1991 & 1992 & 1990 & 1991 & 1992 & 1990 & 1991 & 1992 & 1990 & 1991 & 1992 \\
\hline $0-50 \%$ & & & & \multicolumn{1}{c}{ Vertical intra-industry trade } \\
3 digit & $12^{1}$ & 10 & 9 & 16 & 15 & 20 & 14 & 18 & 19 & 5 & 4 & 3 \\
4 digit & 9 & 5 & 6 & 15 & 8 & 14 & 13 & 11 & 13 & 4 & 1 & 1 \\
5 digit & 3 & 2 & 1 & 7 & 3 & 6 & 3 & 3 & 4 & 6 & 2 & 2 \\
Total & $\mathbf{2 4}$ & $\mathbf{1 7}$ & $\mathbf{1 6}$ & $\mathbf{3 8}$ & $\mathbf{2 6}$ & $\mathbf{4 0}$ & $\mathbf{3 0}$ & $\mathbf{3 2}$ & $\mathbf{3 6}$ & $\mathbf{1 5}$ & $\mathbf{7}$ & $\mathbf{6}$ \\
$50-90 \%$ & & & & & & & & & & & & \\
3 digit & 19 & 21 & 18 & 17 & 21 & 21 & 22 & 26 & 27 & 6 & 10 & 6 \\
4 digit & 9 & 10 & 9 & 15 & 14 & 12 & 32 & 36 & 31 & 9 & 13 & 10 \\
5 digit & 1 & 2 & 1 & 10 & 6 & 4 & 3 & 4 & 5 & 8 & 13 & 3 \\
Total & $\mathbf{2 9}$ & $\mathbf{3 3}$ & $\mathbf{2 8}$ & $\mathbf{5 2}$ & $\mathbf{4 1}$ & $\mathbf{3 7}$ & $\mathbf{5 7}$ & $\mathbf{6 6}$ & $\mathbf{6 3}$ & $\mathbf{2 3}$ & $\mathbf{3 6}$ & $\mathbf{1 9}$ \\
$90-100 \%$ & & & & & & & & & & & & \\
3 digit & 4 & 9 & 10 & 8 & 9 & 6 & 7 & 10 & 6 & 2 & 2 & 3 \\
4 digit & 2 & 2 & 3 & 4 & 6 & 4 & 6 & 9 & 9 & 1 & 1 & 0 \\
5 digit & 0 & 0 & 2 & 2 & 3 & 1 & 3 & 3 & 2 & 2 & 2 & 2 \\
Total & $\mathbf{6}$ & $\mathbf{1 1}$ & $\mathbf{1 5}$ & $\mathbf{1 4}$ & $\mathbf{1 8}$ & $\mathbf{1 1}$ & $\mathbf{1 6}$ & $\mathbf{2 2}$ & $\mathbf{1 7}$ & $\mathbf{5}$ & $\mathbf{5}$ & $\mathbf{5}$ \\
\hline
\end{tabular}

Notes: 1. Number of industry. 2. The squared numbers are the model values in each level of IIT.

Source: Calculated from The International Trade Statistic Yearbook, (various issues).

to export cheaper varieties of a product for which it imports the costlier varieties (Table 5). Since the sample countries are all LDCs, the findings are consistent with a North-South theoretical model where the North produces high quality versions of a product which it export to the South in return for which it imports cheaper Southern varieties of the same product. These observation along with the observation (made in Table 1) regarding the overwhelming dominance of VIIT over HIIT is the main rational behind the actual model that we choose to underpin IIT in LDCs.

Table 6 shows the dispersion of the VIIT industries over commodity categories. It is clear from the table that VIIT industries are mostly clustered around SITC 6(manufactured goods) and SITC 7(Machinery and transport equipment). The model that we present is however more consistent with SITC 6 commodities. It is for this reason that we refer only to this group of commodities while empirically testing the propositions of the model in section 4 .

\section{A Theoretical Model}

The model we use is a version of a model that has a long tradition in economics. 
It was first suggested by Gabszewiez and Thisse $(1978,1979,1982)$ and subsequently applied to international trade by Shaked and Sutton (1989), Flam and Helpman (1987) and more recently by, Stokey (1991), Copeland and Kotwal (1996) and others ${ }^{5}$. There is a vertically differentiated good which is produced under monopoly in autarky and under differentiated product duopoly in free trade. There are two countries $A$ and $B$ one of which is a developed and the other an underdeveloped country. Let A be the developed country. Consumers are assumed to be uniformly distributed along a line in both countries. We assume that there is no R\&D expenditure in $B$ but product quality can be improved through $\mathrm{R} \& \mathrm{D}$ in $A$. the equilibrium for the $D C$ firm has two stages ${ }^{6}$. In the first stage it chooses quality by maximizing profits given its $\mathrm{R} \& \mathrm{D}$ expenditure. Since there is no $\mathrm{R} \& \mathrm{D}$ in $B$ there is no decision variable for $B$ and consequently there is no game at this stage. In the second stage the firms play a quantity game given a constant marginal cost of producing quantity. Given the structure of the model, at the final stage there are only two ways in which the countries (and their monopolist firms under autarky) can differ from the production side $^{7}$, viz., quality and the constant marginal cost. Of the two, quality is more fundamental to the model in the sense that trade is not meaningful with uniform quality and non uniform marginal costs. On the other hand it can be checked that allowing for a difference in quality as well as marginal cost gives no new results though it makes the algebra significantly complicated.

One variety of a vertically differentiated good $X$ is produced in each country. Let the quality of $X$ produced in A be denoted by $q_{A}$ and the quality produced in $B$ by $q_{B}$. Let us initially begin by analysing the second stage of the game, that is, for the moment we assume that the quality levels of the two firms have somehow been chosen and that, since $A$ is the developed country, $q_{A}>q_{B}$, so that $A$ produces a higher quality of the product ${ }^{8}$.

\footnotetext{
${ }^{5}$ Though most of these papers model IIT between developed and underdeveloped countries none of them addresses the issues that we address here. While Flam and Helpman and Stokey analyze North-South trade and highlights the impact of technology, endowments and income distribution on product cycles that change over time, Copeland and Kotwal looks at North-South trade from the perspective of developed countries and tries to find reasons why its magnitude will be smaller (or even be zero) when it is with underdeveloped countries.

${ }^{6}$ Motta (1993) has discussed this model in the context of a closed economy.

${ }^{7}$ Not given the structure, of course, (dis)similarity can be defined in many other ways such as preferences, incomes etc.

${ }^{8}$ The assumption therefore implies that the country doing R\&D activity (the developed country has a better quality. This is of course requires an appropriate assumption on the cost function for producing quality for the developed country. Below we show, with the help of an example, the type of restriction on the cost function that guarantees this.
} 
In the pre-trade situation each producer of $X$ is a monopolist in his own country. The net utility function of a typical consumer consuming the $i$-th variety of $X$ in any country is given by:

$$
U_{i}=q_{i}-(1 / \gamma) P_{i}
$$

where price of the $i$-th product is $P_{i}$ and $\gamma$ is a reservation value for the consumer depending on his income. In particular, $\gamma$ can be interpreted as the inverse of the marginal rate of substitution between income and quality (see Tirole, 1988) formally, $\gamma=1 / U^{\prime}(I)$ where $I$ is the level of income. We assume $U$ to be concave so that $\gamma$ rises with the level of income.

Both countries have a population with varying income levels distributed uniformly between income levels $[\underline{I}, \bar{I}]$. Assuming that the reservation value of the person with the highest $(\bar{I})$ and lowest $(\underline{I})$ incomes are $\bar{\gamma}$ and $\gamma$ respectively, we have a continuum of consumers in each country with reservation values that are distributed uniformly in the interval $(\gamma, \bar{\gamma})$.

The preference structure of the consumers is given as follows. There is a marginal consumer with reservation value $\gamma^{*}$, for whom, the net utility from consuming the $i$-th variety is just equal to zero. Putting $\gamma=\gamma^{*}$ and $U_{i}=0$ in the utility function we get $\gamma_{I}^{*}=P_{i} / q_{i}$. This is the quality adjusted price of the product $i$ whose money price is $P_{i}$.

Consumers whose reservation values exceed $\gamma_{i}^{*}$ purchase one unit of the $i$-th product, while other consumers purchase none. Since the distribution is uniform, the total demand for the $i$-th variety in any country equals the number of people with reservation values exceeding $\gamma_{i}^{*}$, that is in the interval $\left(\gamma_{i}^{*}, \bar{\gamma}\right)$. Since the number of such people is ${ }^{9}\left(\bar{\gamma}-\gamma_{i}^{*}\right)$, that is $\left(\bar{\gamma}-P_{i} / q_{i}\right)$, the demand function for the $i$-th variety in any country is:

$$
P_{i}=\left(\bar{\gamma}-X_{i}\right) q_{i}
$$

$X$ is produced in both countries with a constant marginal cost ' $a$ ' which is the same for all varieties and a fixed cost $F_{i}$, the cost of producing quality ${ }^{10}$. The monopolist producing the $i$-th variety thus has the following profit function:

$$
\Pi_{i}=\left(\bar{\gamma}-X_{i}\right) q_{i} X_{i}-a X_{i}-F_{i}
$$

Profit maximization (given quality) leads to the following price, quantity and

\footnotetext{
${ }^{9}$ We assume without any loss of generality $\bar{\gamma}-\underline{\gamma}=1$

${ }^{10}$ The fixed cost, of course, has no role to play until when quality in $\mathrm{A}$ is endogenised. Also note that $F_{B}$ is equal to zero as the firm in $B$ does not have any R\&D expenditure.
} 
profit solutions:

$$
\begin{gathered}
X_{i}^{A}=\frac{1}{2}\left(\bar{\gamma}-a / q_{i}\right) \\
P_{i}^{A}=\frac{1}{2}(\bar{\gamma}+a) \\
\Pi_{i}^{A}=\frac{1}{4}\left(\bar{\gamma} q_{i}-a\right)\left(\bar{\gamma}-\frac{a}{q_{i}}\right)-F_{i}
\end{gathered}
$$

Where the superscript "A" stands for autarky. Since $\delta^{2} \Pi / \delta X_{i}^{2}=-2 q_{i}<0$, the second order condition is satisfied.

The following points should be noted about the autarky equilibrium specified above. First, as quality of a product rises its money price also rises. Thus in the pre trade situation, $P_{A}>P_{B}$. Second, the restrictions on quality and hence price automatically defines a restriction on $\gamma^{*}$. Recall that $\gamma^{*}=P_{i} / q_{i}$. Thus, in autarky, $\gamma^{*}=1 / 2\left(\bar{\gamma}+a / q_{i}\right)$. Since $q_{A}>q_{B}$ therefore necessarily $\gamma_{A}^{*}>\gamma_{B}^{*}$.

After trade opens up the variety of $X$ produced in $A\left(X_{A}\right)$ becomes available in $B$ and the variety produced in $B\left(X_{B}\right)$ becomes available in $A$. the market structure thus now becomes that of a differentiated product duopolist.

In the post trade situation we have two quality adjusted prices $\gamma_{A}^{*}$ and $\gamma_{B}^{*}$. Let, $\gamma_{A}^{*}>\gamma_{B}^{*}$. Given the structure of demand, this cannot be an equilibrium unless there are some consumers with reservation values greater than $\gamma_{B}^{*}$ but money incomes in the interval $\left(P_{A}, P_{B}\right)$. In such an equilibrium, poor people in both countries purchase the low quality good and get less consumer surplus than they would if they could afford the higher quality good. Consumers with reservation values greater than $\gamma_{B}^{*}$ whose incomes exceed $P_{A}$ will purchase one unit of the high quality good. Combining the two inequalities $\gamma_{B}^{*}>\gamma_{A}^{*}$ and $P_{A}>P_{B}$ gives a necessary condition for such an equilibrium:

$$
P_{B} / P_{A}<q_{B} / q_{A}<1
$$

Given the autarky prices, the only way in which the $B$ firm can have positive sales under free trade is for it to lower its relative price to satisfy this inequality. If it does, it will sell cheap low quality goods in both markets, and the A firm will sell expensive high quality goods in both markets.

Since we have assumed consumers to be distributed directly according to their reservation values rather than incomes, we must determine a critical reservation value $\left(\gamma^{C}\right.$, say) up to which all consumers consume $X_{B}$ and after which consumers 
consumes $X_{A}$. This can easily be done by equating $U_{A}$ and $U_{B}$ and solving the resultant equation for $\gamma\left(=\gamma^{C}\right)$. Thus,

$$
\gamma^{C}=\left(P_{A}-P_{B}\right) /\left(q_{A}-q_{B}\right)
$$

Note that, if inequality (3) holds then, $\gamma^{C}>\gamma_{A}^{* 11}\left(>\gamma_{B}^{*}\right)$. Thus there are indeed consumers in both countries who choose $X_{B}$ even though $X_{B}$ is available. Given $\gamma^{C}$, the total demand for $X_{B}$ in any country is the number of consumers between $\left(\gamma_{B}^{*}, \gamma^{C}\right)$ and the demand for $X_{A}$ is the number of consumers in the interval $\left(\gamma^{C}, \bar{\gamma}\right)$. Consumers in the interval $\left(\underline{\gamma}, \gamma_{B}\right)$ do not consume $X$, that is, choose to retain their income $^{12}$.

Given inequality ( 3$)^{13}$ the total demand for $X_{A}$ and $X_{B}$ in the post trade situation is given by ${ }^{14}$ :

$$
\begin{gathered}
X_{A}=2\left\{\bar{\gamma}-\left(P_{A}-P_{B}\right) /\left(q_{A}-q_{B}\right)\right\} \\
X_{B}=2\left\{\left(P_{A}-P_{B}\right) /\left(q_{A}-q_{B}\right)-\left(P_{B} / q_{B}\right)\right\}
\end{gathered}
$$

For clarity, the above discussion can be summed up in the following lemma:

LEMMA I: If $q_{A}>q_{B}$ and firms in $A$ and $B$ both have positive demand for their products (IIT is possible) then (a) $P_{A}>P_{B}$ and (b) $\left(P_{A} / P_{B}\right)>\left(q_{A} / q_{B}\right)$, that is, inequality (3) must be satisfied and (c) the demand function for $A$ and $B$ are given by the above two equations.

PROOF: The proof follows from the above discussion.

Solving the above two equations the inverse demand functions for $X_{A}$ and $X_{B}$ are:

$$
P_{A}=\left(q_{A}-q_{B}\right)\left(\bar{\gamma}-1 / 2 X_{A}\right)+1 / 2 q_{B}\left(2 \bar{\gamma}-X_{A}-X_{B}\right)
$$

${ }^{11}$ Note that this means $\left\{\left(P_{A}-P_{B}\right) /\left(q_{A}-q_{B}\right)\right\}>P_{A} / q_{A}$ or, $\left(P_{B} / P_{A}\right)<\left(q_{B} / q_{A}\right)$.

${ }^{12} \mathrm{~A}$ condition required for this specification to yield positive demand for both $X_{A}$ and $X_{B}$ is: $\bar{\gamma}>\gamma^{C}>\gamma_{A}^{*}>\gamma_{B}^{*}$. It can be checked that this inequality is guaranteed by (3) which we assume to be true.

${ }^{13}$ Of course, two other cases are possible:

I. If $\gamma_{B}^{*}>\gamma_{A}^{*}$ then $\gamma_{B}^{*}>\gamma_{A}^{*}>\gamma^{C}$ and $1>\left(P_{B} / P_{A}\right)>\left(q_{B} / q_{A}\right)$. Under such circumstances B will not have a market at all and we have a homogeneous product monopolist (belonging to $A$ ) serving the entire of the market, both in the LDC as well as the DC. There will only be one way trade, with products flowing from the $\mathrm{DC}_{*}$ to the $\mathrm{LDC}$ in this industry.

II. If $\gamma_{B}^{*}=\gamma_{A}^{*}$ then $\gamma_{B}^{*}=\gamma_{A}^{*}=\gamma^{C}$ and $1=\left(P_{B} / P_{A}\right)=\left(q_{B} / q_{A}\right)$. which violates our basic assumption that $q_{A}>q_{B}$.

Since our primary concern is trade in differentiated products we do not consider these cases here.

${ }^{14} X_{A}=\int d \gamma$ and similarly for $X B$ 


$$
P_{B}=1 / 2 q_{B}\left(2 \bar{\gamma}-X_{A}-X_{B}\right)
$$

Since our primary concern in this section and the next two sections is with the difference in quality between $X_{A}$ and $X_{B}$ rather than their absolute magnitudes, we assume, without loss of generality, that $q_{A}=1$ and $q_{B}=\beta(\beta<1)$. Under the circumstances (4) reduces to:

$$
P_{A}=(1-\beta)\left(\bar{\gamma}-1 / 2 X_{A}\right)+1 / 2 \beta\left(2 \bar{\gamma}-X_{A}-X_{B}\right)
$$

The profit functions of the two firms are:

$$
\begin{gathered}
\Pi_{A}=(1-\beta)\left(\bar{\gamma} X_{A}-1 / 2 X_{A}^{2}\right)+1 / 2 \beta X_{A}\left(2 \bar{\gamma}-X_{A}-X_{B}\right)-a X_{A}-F_{i} \\
\Pi_{B}=1 / 2 \beta\left(2 \bar{\gamma}-X_{A}-X_{B}\right) X_{B}-a X_{B}-F_{i}
\end{gathered}
$$

the profit maximizing duopolist, equate their respective marginal revenues to their marginal costs. We assume that firms choose quantities. The resultant Cournot Nash equilibrium is given by the following two reaction functions:

$$
\begin{gathered}
X_{A}+2 X_{B}=2(\bar{\gamma}-a / \beta) \\
2 X_{A}+\beta X_{B}=2(\bar{\gamma}-a)
\end{gathered}
$$

Solving these the post trade equilibrium price quantity and profits are given by:

$$
\begin{gathered}
X_{A}^{T}=\frac{2}{4-\beta}[\bar{\gamma}(2-\beta)-a] \\
X_{B}^{T}=\frac{2}{4-\beta}\left[\bar{\gamma}+a\left(1-\frac{2}{\beta}\right)\right] \\
P_{A}^{T}=\frac{1}{4-\beta}[2 \bar{\gamma}(1-\beta)+a(3-\beta)] \\
P_{B}^{T}=\frac{\beta}{4-\beta}\left[\bar{\gamma}(\beta-2)+\frac{2 a}{\beta}\right] \\
\Pi_{A}^{T}=\frac{1}{(4-\beta)^{2}}[2 \bar{\gamma}(1-\beta)+a(3-\beta)-a(4-\beta)][2 \bar{\gamma}(2-\beta)-2 a] \\
\Pi_{B}^{T}=\frac{1}{(4-\beta)^{2}}[2 \bar{\gamma}(1-\beta)+a(3-\beta)-a(4-\beta)][2 \bar{\gamma}(2-\beta)-2 a]
\end{gathered}
$$

Where the superscript " $T$ " stands for solution in the post trade situation. For (7) to (12) to be a trading equilibrium, $X_{A}^{T}$ and $X_{B}^{T}$ must be positive and inequality (3) should be satisfied. For the former we require (from (7) and (8)) $(\bar{\gamma} / a>(2 / \beta)-$ 
1. Putting (9) and (10) in (3) we find that, for the later we require $(\bar{\gamma} / a>(2+\beta$ $\left.{ }^{2}-3 \beta\right) /\left(4 \beta-3 \beta^{2}\right)$. Of the two $\gamma / a>(2 \beta)-1$ is binding as it is greater of the two. Thus:

LEMMA II: For the existence of a differentiated product duopoly equilibrium consisting of (7) to (12) in the post trade situation the following condition must be satisfied:

$$
\gamma / a>(2 / \beta)-1
$$

PROOF: This follows directly from equations (7)-(10) and inequality (3). Further, Since:

$$
\Pi_{A B}=-(1 / 2 \beta)=\Pi_{B A}
$$

therefore own marginal revenue declines when the other firm increases its output. Thus the reaction functions are negatively sloping and the equilibrium is stable.

Since consumers in both countries have the same preferences and both countries have the same income distribution exactly half of each firm's output is sold at home and the other half is exported. Thus total trade in similar products or $I I T$ for any country is equal to $\left(X_{A}^{T}+X_{B}^{T}\right) / 2$ where $X_{A}^{T}$ and $X_{B}^{T}$ are given by equations (7) and (8).

Now let $\bar{I}$ (and hence $\bar{\gamma}$ ) increase. Since people added at the upper end of the income spectrum, therefore per capita income of the population increase in both the countries. We can then note the following observation:

OBSERVATION 1: An increase in per capita income in the trading partners increase IIT.

Proof: This follows directly from the definition of IIT in this model and equations (7) and (8).

\section{An Example}

Let us now consider the process by which the firm in A chooses quality by $R \& D$ in the post trade situation ${ }^{15}$. Let us assume that i) $a=0$ and ii) $\bar{\gamma}=1$ and $\gamma=0$. Under the circumstances the profit functions of the two firms are:

$$
\begin{gathered}
\Pi_{A}=\left(q_{A}-q_{B}\right)\left\{X_{A}-(1 / 2) X_{A}^{2}\right\}+(1 / 2) X_{A} q_{B}\left(2-X_{A}-X_{B}\right)-F \\
\Pi_{B}=q_{B} X_{B}-(1 / 2) q_{B} X_{A} X_{B}-(1 / 2) q_{B} X_{B}^{2}
\end{gathered}
$$

Where $\mathrm{F}$ is A's R\&D expenditure which is a fixed cost at this stage.

The equilibrium price and quantity solutions are:

\footnotetext{
${ }^{15}$ The firm in $B$ cannot choose quality as it has no R\&D expenditure.
} 


$$
\begin{gathered}
X_{A}=2\left(2 q_{A}-q_{B}\right) /\left(4 q_{A}-q_{B}\right) ; X_{B}=2 q_{A} /\left(4 q_{A}-q_{B}\right) \\
P_{A}=q_{A}\left(2 q_{A}-q_{B}\right) /\left(4 q_{A}-q_{B}\right) ; P_{B}=q_{A} q_{B} /\left(4 q_{A}-q_{B}\right)
\end{gathered}
$$

Since there is no R\&D expenditure in the firm in $B$ therefore $q_{B}$ is exogenous $q_{B}=\bar{q}_{B}$. Let the cost function for producing quality in $A$ be represented by $C\left(b, q_{A}, q_{B}\right)$. Where $b$ is a parameter. We assume

$$
\frac{\delta C}{\delta q_{A}}<0 \text { and } \frac{\delta C}{\delta \bar{q}_{B}}<0 .{ }^{16}
$$

The first stage profit function for $A$ is:

$$
\Pi_{A}=\frac{2\left(2 q_{A}-\bar{q}_{B}\right)^{2}}{\left(4 q_{A}-\bar{q}_{B}\right)^{2}}<C\left(q_{A}, \bar{q}_{B}\right)
$$

Let the equilibrium $q_{A}$ available from maximizing profit be:

$$
q_{A}=f\left(\bar{q}_{B}, C_{q A}\right), f_{q B}>0, f_{C q A}^{17}<0
$$

Where $C_{q A}\left(=\delta C / \delta q_{A}\right)$ is the marginal cost of producing $q_{A}$. As it has been shown in the example considered below an appropriate assumption on $C_{q A}$ can guarantee a higher quality for $A$ than $B$.

From (13) and (14) the total amount of IIT is:

$$
I I T=\frac{1}{2}\left(X_{A}+X_{B}\right)=\frac{3 f\left(\overline{q_{B}}, C_{q A}\right)-\overline{q_{B}}}{4 f\left(\overline{q_{B}}, C_{q A}\right)-q_{B}}
$$

Differentiating (16) w.r.t. $C_{q A}$ and $\bar{q}_{B}$ we get:

$$
\begin{gathered}
\frac{\delta I I T}{\delta C_{q A}}=\frac{f_{C q A} \bar{q}_{B}}{\left(4 q_{A}-\bar{q}_{B}\right)^{2}} \\
\frac{\delta I I T}{\delta \bar{q}_{B}}=\frac{f_{q B} \bar{q}_{B}-f(\bullet)}{\left(4 q_{A}-\bar{q}_{B}\right)^{2}}
\end{gathered}
$$

Where $f_{C q A}=\delta f(\bullet) / \delta C_{q A}$. Using (16) we have proved the following proposition:

OBSERVATION 2: (a) Intra industry trade increases with technical progress in the developed

\footnotetext{
${ }^{16}$ To increase quality the firm has to incur higher cost but there is a spill over effect of a rise in the quality of the competitor.

${ }^{17}$ As marginal cost of producing quality increase quality produced falls.
} 
country.

(b) If $f_{q B}>q_{A} / \bar{q}_{B}{ }^{18}$ then IIT increases with economic development of the underdeveloped country ${ }^{19}$.

The two observations mentioned above establishes a positive relationship between IIT and economic development of the trading partners ${ }^{20}$. In the rest of the paper we will test for this relationship with the data on vertical IIT presented in the previous section $^{21}$.

\section{Results}

In what follows we drop one country considered in the previous section viz., Chile from the analysis as for it data regarding the percentage share of industry in $G D P$ (the variable $I N D$ ) is not available for all the sample years. The simple regression results of VIIT with GNP and IND are $^{22}$ :

\footnotetext{
${ }^{18} \mathrm{As} q_{B}$ increases $q_{A}$ increases faster than $q_{B}\left(\right.$ as $\left.q_{A} / q_{B}>1\right)$, that is, as dissimilarity between the countries increase.

${ }^{19}$ Note that these are sufficiency conditions not necessary conditions.

${ }^{20}$ Let the cost function be: $C\left(b, q_{A}, q_{B}\right)=b\left(q_{A}-\bar{q}_{B}\right) /\left(4 q_{A}-\bar{q}_{B}\right)$. Note that $\delta C / \delta q_{A}>0$ and $\delta C / \delta \bar{q}_{B}<0$. Equilibrium $q_{A}=\left\{\bar{q}_{B}(8-3 b)\right\} /\{4(4-3 b)\}$ so that $f_{q B}=(8-3 b) /\{4(4-3 b)\}>0, f_{C q A}=-\left\{\left(4 q_{A}-\bar{q}_{B} /\right.\right.$ $\left.24 \mathrm{~b} \bar{q}_{B}\right\}<0$ and, $q_{A}>q_{B}$ for $b>8 / 9$. Finally, $I I T=(8-3 \mathrm{~b}) / 4$ so that $\delta I I T / \delta b=-3 / 4<0$. Since $\delta C_{q A} /$ $\delta b=3 q_{B} /\left(4 q_{A}-\bar{q}_{B}\right)>0$ therefore $\delta I I T / \delta C_{q A}<0$. However IIT is free of $q_{B}$.

${ }^{21}$ Some writers have tested this hypothesis (see, for example, Havrylyschin and Civan (1983), Helpaman and Krugman (1985), chapter 8) using the horizontal IIT model as the theoretical backdrop for such tests. The hypothesis has not been tested for vertical IIT as this paper intends to do.

${ }^{22}$ Since IIT is a positive fraction some statistical problems are expected if we run an OLS regression with it as the dependent variable. For example, it has been pointed out by several writers (see, for example, Bergstrand, 1983) that since the explanatory variables are assumed to be non-stochastic, the only source of randomness in $I I T_{i}$ is the random error term, say, ui. However the latter, in turn, is assured to have a standard normal distribution, defined over a range $(-\propto,+\propto)$. The net impact of this is therefore that while ui can take any value on the real number plane, IIT, its linear combination in the regression equation, can only take values in a limited range.
}

To overcome this, problem Bergstrand (1983) suggests a logit transformation:

$I I T_{i}=\left[\left\{\exp \left(x_{i} \beta\right)\right\} /\left\{1+\exp \left(x_{i} \beta\right)\right\}\right] \cdot u_{i}$

where $u_{i}$ 's are homoscedastic disturbance terms. This implies that:

$\ln \left\{I I T_{i} /\left(1-I I T_{i}\right)\right\}=x_{i}^{\prime} \beta+\ln \left\{u_{i} /\left(1-u_{i}\right)\right\}$

$=x_{i}^{\prime} \beta+\varepsilon_{i}($ say $)$

assuming $Z_{i}^{1}=\ln \left\{I I T_{i} /\left(1-I I T_{i}\right)\right\}$ we regress $Z_{i}^{1}$ on the independent variables. However, for the transformed regression the random error term $\varepsilon_{i}=f\left(u_{i}\right) \sim N\left(\theta, f^{\prime} \delta_{u}^{2}\right)$. Thus, $V\left(\varepsilon_{i}\right)=\sigma_{u}^{2} /\left\{I I T_{i} /\right.$ $\left.\left(1-I I T_{i}\right)\right\}$ and the transformed model has heteroscedastic disturbances. Application of OLS will obviously lead to unbiased but inefficient estimates. So, while running the regression we will have to apply WLS with $\{\text { IIT. }(1-I I T)\}^{1 / 2}$ as weights. However, we continue to denote the adjusted dependent and the independent variables by their original titles. Thus, in what follows, IIT, GNP and IND are not the original variables, but the variables with the above adjustments. 
Table 7. The Estimated Model with GNP Dummies

\begin{tabular}{|ccrrrr|}
\hline Variable & Coefficient & T ratio & Variable & Coefficient & T ratio \\
\hline GD1 & -.0074 & 1.01 & GD9 & & 2.41 \\
GD2 & -.0063 & 0.69 & GD10 & 0.0003 & -6.15 \\
GD3 & -.0030 & -2.48 & GD11 & 0.00007 & -2.16 \\
GD4 & -.0017 & -4.69 & GD12 & -0.00006 & -1.65 \\
GD5 & -.0016 & -1.47 & GD14 & 0.00012 & 5.46 \\
GD6 & --.0013 & -3.99 & GD15 & 0.0002 & 8.47 \\
GD7 & -.0005 & -1.62 & GNP & -0.00002 & -0.86 \\
GD8 &.- .0007 & -2.04 & CONS & -.1890 & -10.14 \\
\hline
\end{tabular}

Notes: $1 . \mathrm{R}^{2}=.95$ and $\left(\bar{R}^{2}=.942\right.$. Heteroscadasticity consistent covariance matrix used.

Table 8. The Estimated Model with Industry Dummies

\begin{tabular}{|cccccc|}
\hline Variable & Coefficient & T ratio & Variable & Coefficient & T ratio \\
\hline $\mathrm{ID}_{1}$ & -.0951 & -2.369 & ID8 & -.0717 & -5.240 \\
$\mathrm{ID}_{2}$ & -.0952 & -1.923 & ID9 & -.0546 & -4.781 \\
$\mathrm{ID}_{3}$ & -.0770 & -5.268 & ID11 & -.0262 & -1.978 \\
$\mathrm{ID}_{4}$ & -.0681 & -4.620 & ID12 & -.0284 & -2.170 \\
$\mathrm{ID}_{5}$ & -.0814 & -4.658 & IND & -0.015 & -3.08 \\
$\mathrm{ID}_{6}$ & -.0757 & -5.623 & CONS & -.393 & -1.544 \\
$\mathrm{ID}_{7}$ & -.0574 & -4.902 & & & \\
\hline
\end{tabular}

Notes: $1 . R^{2}=.95$ and $\left(\vec{R}^{2}=.942\right.$. Heteroscadasticity consistent covariance matrix used.

Table 9. IIT and Economic Development: Income Group Based Classification ${ }^{1,3,5}$

\begin{tabular}{|cccccc|}
\hline Group & Cons. & GNP & IND & $\overline{\boldsymbol{R}}^{2}$ & COR $^{4}$ \\
\hline & $\begin{array}{c}-0.58 \\
\left(-23.4^{*}\right)\end{array}$ & $\begin{array}{c}-0.0002 \\
(-2.1)\end{array}$ & & 0.12 & 0.77 \\
Low and Lower Miiddle & $\begin{array}{c}-0.55 \\
\left(-10.1^{*}\right)\end{array}$ & & $\begin{array}{l}-0.007 \\
(-1.06)\end{array}$ & 0.09 & \\
Upper middle and High & $\begin{array}{c}-1.10 \\
\left(-2.9^{*}\right)\end{array}$ & $\begin{array}{c}0.00006 \\
(2.37)\end{array}$ & $\begin{array}{c}.04 \\
\left(2.11^{*}\right)\end{array}$ & 0.17 & 0.06 \\
\end{tabular}

Notes: 1 . Figures in brackets are $\mathrm{t}$ values. 2 . $\mathrm{t}$ values for the correlation coefficient is calculated by using the following formula: $t=r \sqrt{(n-2)} / \sqrt{\left(1-r^{2}\right)}$. A significant $t$ value is assumed to be a conclusive proof for multicollinearity in the model. The explanatory variables are estimated separately in such cases. 3 . *Implies accepted at 5\% level and **Implies accepted at $10 \%$ level. 4. Correlation between GNP and IND. 5. Chow's test for stability of coefficients between (1) Low and Lower middle is $25.39^{*}$ for regression with $G N P$ and $12.45^{*}$ for regression with IND, (2) Lower middle and Upper middle: 2.63 and 1.92 and (3) Upper middle and high: $35.64 *$ for regression with GNP and IND together.

The above equation ${ }^{23}$ shows a strongly positive relationship between vertical IIT and the level of economic development. Coming now to the country effects ${ }^{24}$, the estimated results are presented in Tables 7 and 8 . Since we have taken a 
relatively developed country (Korea) as the base country the negative signs in front of the differential coefficients are expected ${ }^{25}$ and they reinforce our contention regarding the positive relationship between economic development and IIT.

Finally we report the above relationship at the sub-group level. There are two sub-groups in our case. First the subgroup consisting of lower and lower-middle income countries and second, the subgroup consisting of upper-middle and high income $\mathrm{LDCs}^{26}$. The results for these groups are presented in Table 9. It is clear

${ }^{23}$ The regressions are run seperately as the correlation between the GNP and IND is a significant .65 . The value of the chi-square varite in the $O L S$ regression on the entire data set involving all the twelve countries (and with GNP and IND as the explanatory variables respectively) turns out to be 3.63 and 4.25 which clearly rejects the null hypothesis of homoscedasticity at the one percent level of significance. A correction for heteroscedasticity is done by using the degrees of freedom adjusted version of White's $(1980,1982)$ heteroscedasticity consistent estimates of the variance - covariance matrix.

${ }^{24}$ For the fixed effects model we can use the following general dummy variable specification:

$y_{i t}=\sum_{i} D_{j t} \beta_{0 j}+\sum_{i} D_{j t} x_{l j t} \beta_{l j}+\sum_{i} D_{j t} x_{2 j t} \beta_{2 j}+\varepsilon_{i}$

where $i, j=1,2, . ., 15, \mathrm{t}=1,2, . ., 6$ and $x_{1}$ and $x_{2}$ are the explanatory variables $(G N P$ and $I N D) . D_{i j}$ is defined as:

$D_{j t}=1$ for country $j$

$=0$ otherwise

Two problems are to be noted about the above specification. First, the specification will involve the introduction of forty five new variables within the model which would severly affect the degrees of freedom and would have its consequent adverse effect on the robustness of the estimators. A better alternative might be to use one set of dummies at a time and hence to estimate three separate equations from the above generalized formulation. Secondly, a slight reparameterization of the model involving a constant term and with one less dummy variable from each set would be useful in assessing the differential effects. This estimate with a constant term is also required by several computer packages. The country without dummy is called the "base" country.

Reparameterizing the model with the above observations in mind and taking Korea (country no. 13) as the base the regression with intercept dummy becomes:

$y_{i t}=\beta_{0,13}+\sum_{j \neq 13} D_{j t} \beta_{0, j}+\beta_{1} x_{1, j t}+\beta_{2} x_{2, j t}+\varepsilon_{i t} ; j=1 \ldots 15, t=1 \ldots 6$

We can similarly write down the relevant regression equations for the slope dummy on GNP and IND respectively as:

$$
\begin{aligned}
& y_{i t}=\beta_{0,13}+\sum_{j \neq 13} D_{j t} \beta_{0, j}+\beta_{1} x_{1, j t}+\beta_{2} x_{2, j t}+\varepsilon_{i t} ; j=1 \ldots 15, t=1 \ldots 6 \\
& y_{i t}=\beta_{0}+\beta_{1,13} x_{1,13 t}+\sum_{j \neq 13} D_{j t} \beta_{1, j} x_{1, j t}+\beta_{2} x_{2, j t}+\varepsilon_{i t} ; j=1 \ldots 15, t=1 \ldots 6
\end{aligned}
$$

and

$$
y_{i t}=\beta_{0}+\beta_{1} x_{1, j t}+\beta_{2,13} x_{2,13 t}+\sum_{j \neq 13} D_{j t} \beta_{2, j} x_{2, j t}+\varepsilon_{i t} ; j=1 \ldots 15, t=1 \ldots 6
$$

${ }^{25}$ All countries which are economically less developed than the base country should have a negative slope and all countries which are more developed should have a positive slope.

${ }^{26} \mathrm{The} \chi^{2}$ value for the Chow test for the stability of the regression coefficients across groups (1) for GNP is 4.9 and (2) for IND is 9.03 both of which are significant at the $10 \%$ level. 
from the table that no meaningful relationship exists between economic development and vertical IIT for the first group but the relationship holds strongly for the second group. Thus the relationship between economic development and vertical IIT depends on the absolute level of economic development of the trading countries.

\section{Analysis of the Pattern of Data Fluctuations}

Now that we know that there is a positive relationship between economic development and vertical IIT, given our data set, can we infer something about the pace at which vertical IIT responds to economic development? The sub-group level analysis seems to suggest that, IIT initially does not respond to economic development at all, however, after it crosses a threshold value of economic development, it begins to do so and after that the relationship is stable. Does this mean that as economic development progresses the rate of response of VIIT to economic development progressively rises $?^{27}$ Let us first note that we have adjusted the data set for our analysis. That is, the basic model that we work with in the pooled sample is:

$$
\ln (I I T /(1-I I T))=a+b_{1} G N P+b_{2} I N D
$$

That is, IIT $=e^{r} /\left(1+e^{r}\right)$ where $r=a+b_{1} G N P+b_{2}$ IND. First note that as $r \rightarrow$ 0 IIT $\rightarrow .5$ and as $\mathrm{r}$ becomes large $I I T \rightarrow 1$ (which is its maximum value and which it achieves at a finite $G N P$ ). Also as $r \rightarrow-\mu, I I T \rightarrow 0$. Secondly, differentiating the above equation partially with respect to $r$ we have:

$$
\frac{\delta I I T}{\delta P}=\frac{e^{\rho}}{\left(1+e^{\rho}\right)}>0
$$

Now as $r \rightarrow 0, e^{r} /\left(1+e^{r}\right)^{2} \rightarrow .25$, as $\mathrm{r} \rightarrow \mu, e^{r} /\left(1+e^{r}\right)^{2} \rightarrow 0$ and as $r \rightarrow-\mu, e^{r} /$ $\left(1+e^{r}\right)^{2} \rightarrow 0$. Now since $d I I T / d G N P=b_{1} e^{r} /\left(1-e^{r}\right)$ and $d I I T / d I N D=b_{2} e^{r} /\left(1-e^{r}\right)$, assuming $b_{1}$ and $b_{2}$ to be both positive, the maximum value that $d I I T / d G N P$ and dIIT/dIND can achieve is $b_{1} / 4$ and $b_{2} / 4$. This they achieve at very low levels of

\footnotetext{
${ }^{27}$ Note that this is not an unreasonable presentation as economic growth itself demonstrates Kaldor's (1963) contention that per capita output grows over time, and its growth rate does not tend to diminish. Barro and Sala-i-Martin (1995) points out that Kaldor's statement "Seems to fit reasonably well with the long term data of currently developed countries" (p. - 5).
} 
$G N P$ and IND respectively. With higher GNP and IND the growth rate falls and asymptotically approaches zero as the variables become very large. Finally,

$$
\frac{\delta^{2} I I T}{\delta P^{2}}=\frac{e^{\rho}\left(1-2^{\rho}\right)}{\left(1+e^{\rho}\right)^{4}}
$$

which is negative for $r>-\ln 2$ (corresponding to $I I T>(-\ln 2 /(1-\ln 2)=) .33)$ but positive for $r<-\ln 2$ (IIT<.33).

Assuming for the moment that the first order differentiation of IIT with respect to a variable is a measure of the 'growth' rate of IIT with respect to these variables we can say that the structure of our model suggests that IIT increases at a decreasing rate with respect to $r$ (which we have assumed to be a positive function of $G N P$ and IND) in the interval $[.5,1]$ with a maximum 'growth' rate of 0.25 with respect to $r$ which it achieves at $r=0$. This in turn implies that the maximum growth rate of GNP and IND is $b_{1} / 4$ and $b_{2} / 4$ respectively achieved at very low levels of the variables-the rate continuously falling as these variables rise.

The rate of fluctuation of IIT that we have considered above is rigidly given by the structure of the model with which we are working. The only thing that we could estimate were the maximum values of the partial derivatives of IIT with respect to $G N P$ and $I N D^{28}$. This seems to be unsatisfactory to the extent that we could not test the validity of the 'increasing at a decreasing rate' hypothesis that the model imposes upon us. Below we re-analyse the data independently of the model to arrive at a conclusion regarding it. To make the analysis more general we also calculate the growth rate of the total trade volume in manufacturing and compare it with the growth rate of IIT both with respect to GNP and GDP to determine which has increased at a faster rate. For this we estimate the following equation:

$$
\ln I I T=a+b \ln G N P
$$

where $b$ is the elasticity of $I I T$ with respect to GNP and $b>1$ implies that the relationship between IIT and GNP is as follows: as GNP grows IIT grows at a faster rate ( $d I I T / d G N P, d^{2} I I T / d G N P^{2}>0$ ) (this is because, say, $g=I I T / G N P$ and $q=d I I T / d G N P$ so that $b=q / g$. Obviously the above hypothesis implies that $q>$ $g$ implying that $b>1$. On the other hand $b<1$ implies the opposite).

\footnotetext{
${ }^{28}$ Given the estimated equation in section 4 this implies that the maximum growth rates of GNP and IND are respectively.0005 and.175 (in percentages).
} 
Table 10. Estimates for Growth Rates of Total Trade Volume in Manufacturing and IIT over GNP per Capita and Gross Domestic Product $(G D P)^{1}$

\begin{tabular}{|lrrrrrr|}
\hline \multirow{2}{*}{ Group } & \multicolumn{3}{c}{ IIT's growth w.r.t. } & \multicolumn{3}{c|}{ TOT's growth w.r.t. } \\
\cline { 2 - 7 } & $G N P^{3,5}$ & $G D P^{5}$ & $\mathrm{R}^{2^{4,5}}$ & $G N P^{3,5}$ & \multicolumn{1}{c|}{$G D P^{5}$} & $\mathrm{R}^{2^{4}}$ \\
\hline 1. Low+Low-Mid & $.13(1.12)$ & $.24(1.77)$ & $.062(.14)$ & $-.10(-.52)$ & $.62(3.10)$ & $.014(.33)$ \\
2. Up-Mid+High & $.21(3.84)$ & $.07(1.85)$ & $.53(.20)$ & $1.75(4.26)$ & $.71(2.59)$ & $.58(.34)$ \\
Total & $.09(1.9)$ & $.11(1.95)$ & $.10(.11)$ & $.51(3.29)$ & $.67(3.67)$ & $.24(.28)$ \\
\hline
\end{tabular}

Notes: 1. Estimates of intercepts not reported. 2. Total trade volume. 3. GNP per capita. 4. Figures outside brackets are the $R^{2}$ for the regression on GNP. Figures within brackets are $R^{2}$ for GDP. 5. Figures in brackets are t values.6. Observations 1-21 is group 1, observations 22-36 is group 2 .

Table 10 reports the results for the above growth rate. There is no relationship between the rates of fluctuation between GNP and IIT for the two lower groups the first of which do not have any statistically significant relationship between these variables at the level as well. However, the rates of fluctuation support the 'increasing at a decreasing hypothesis' for the upper two groups as well as the entire sample implying that our assumption regarding a falling growth rate of IIT with respect to GNP and IND which was implied by the choice of our model is not a bad one. Thus as per capita gross national product of equivalently the purchasing power of the masses increase IIT increases at a slower rate than the increase in the purchasing power.

It is well known that for $O E C D$ countries trade in manufacturing has increased faster than GDP. For the pooled data with which we are working here table 10 however shows that this is not true for $L D C s$. It has "grown"29 at a slower rate than both GDP and GNP per capita like in case of IIT (except for the high income countries where the growth rate, which is still lower but not significant). Also note that total volume of trade has always grown at a faster rate than IIT both over $G N P$ and GDP and the $R^{2}$,s are always high for equations with total trade volume (TOT) as the dependent variable.

\section{Conclusion}

This paper suggests that for LDCs vertical IIT dominates horizontal IIT. A theoretical model consistent with this finding suggests that, unlike what

\footnotetext{
${ }^{29}$ Strictly speaking we should not be using the word "growth" as it is usually a word reserved for fluctuation over time alone not over a pooled data set. However in this paper we use the word broadly and not in the usual sense in which it is used in economics.
} 
Loertscher and Wolter (1980) suggested for IIT of the mixed variety, vertical IIT has a strong positive relationship with the extent of economic development of the trading countries. a rigorous look at the data set confirms that there is indeed a positive relationship between economic development and IIT for the LDCs. At the aggregate level the growth rate of IIT falls as we move to countries with increasing levels of development. This is partly due to the fact that there is an upper bound to the IIT index and partly due to the reason that as IIT grows to very high levels the number of industries which are potentially capable of generating IIT but not doing so progressively falls. In other words as IIT increases with economic development the scope for further increase in IIT falls as the avenues get exhausted. Importantly however the paradigm that 'low income countries have high growth rates' cannot be taken too literally as the low income countries do not necessarily have a more significant relationship with respect to all the indicators of economic development we have considered here. The relationship with respect to per capita GNP is fuzzy for the countries with the lowest levels of incomes in the sample. This aberration however does not stop the result regarding growth rates from going through in the larger sense - it only suggest that the subgroups have their own special characters. Our analysis also suggests that that though IIT grows with economic development it does not grow as fast as total trade volume in manufacturing does implying that inter industry trade is still a large and growing segment of total trade in manufacturing in LDCs.

\section{Acknowledgement}

I am deeply indebted to Sarmila Banerji, Tathagata Banerji, Abhirup Sarkar, Kunal Sengupta and Surekha Rao for discussions and comments.

Date accepted: July 2001

\section{References}

Barro, R.J. and Sala-i-Martin, X. (1995), Economic Growth, McGraw Hill, New York. Bergstrand, J.H. (1983), "Measurement and Determinants of Intra-Industry Trade" in PKM Tharakan (Ed) Intra-Industry Trade: Empirical and Methodological Aspects. Amsterdam. pp 281-300.

Caves, R.E. (1981), "Intra Industry Trade and The Market Structure In Industrial Countries" Oxford Economic Papers. 33, 203-223. 
Copeland, B.R. and Kotwal, A. (1996), "Product quality and the Theory of Comparative advantage". European Economic Review. Dec, 1745-1760.

Davis, R.D. (1995), "Intra-Industry Trade: A Heckscher-Ohlin-Ricardo Approach:", Journal of International Economics, 39, 201-226.

Falvey R.E and Kierzkowski, H. (1987), "Product Quality Intra Industry Trade and (im)perfect Competition" in H. Kierzkowski (Ed.) Protection and Competition in International Trade. Basil Blackwell. Oxford, 143 -164.

Finger, J.M. and DeRosa, D. (1979), "Trade Overlap, comparative Advantage and Protection". In H. Giersch (Ed.) On the Economics of Intra Industry trade. Tubingen, 213-240.

Flam, H. and Helpman, E. (1987), "Vertical Product Differentiation and North - South Trade". American Economic Review. (December), 810-822.

Gabszewicz, J.J. and Thisse, J.F. (1979), "Price Competition. Quality and Income Disparities". Journal of Economic Theory., 20, 340-359.

(1982), "Product Differentiation With Income

Disparities: An Illustrative Model”. The Journal of Industrial Economics, 31(1/2), 115-129.

Greenaway, D., Hine, R. and Milner, C. (1994), "Country Specific Factors and The Pattern of Horizontal and Verical Intra-Industry Trade in the UK", Weltwirtschaftliches Archiv., 130, 78-100.

(1995), "Vertical and Horizontal Intra-Industry

Trade: A Cross Industry Analysis for the United Kingdom”, Economic Journal, 105, 1505-1518.

Grubel, H. and Lloyd, P.J. (1975), Intra Industry Trade: The Theory and Measurement of International trade in differentiated Products. Macmillan. London.

Havrylyschyn, O. and Civan, E. (1983), "Intra Industry trade and The Stages of Development: A Regression Analysis of Industrial And Developing countries." in P.K. Tharakan (Ed) Intra Industry Trade: Empirical and Methodological Aspects Amsterdam, 111-140.

Helpman, E. (1987), "Imperfect Competition and International Trade: Evidence From Fourteen Industrialized Countries". Journal of Japanese and International Economics. 1.

Jones, R. Marjit, S. and Beladi, H. (1998), “Three Faces of Factor Intersities”, University of Rochester (mimeo).

Kaldor, N. (1963), "Capital Accumulation and Economic Growth" in F.A. Lotz and D.C. Hagve (Eds) Proceedings of a Conference held by the International Economic Association, Macmillan, London.

Loertscher, R. and Wolter, F. rminants of Intra Industry Trade Among countries and Across Industries" Weltwirtschaftliches Archiv., 116, 281-293.

Leamer, E.E. and Levinson, J. (1995), "International Trade Theory: The Evidence" in G.M. Grossman and K. Rogoff (Ed.) Handbook of International Economics, 3, 13391394. 
Motta, M. (1993), “Endogenous Quality Choice: Price vs Quantity Competition”, The journal of Indutrial Economics, xli, 113-131.

Shaked, A. and Sutton, J. (1989), "Natural Oligopolies and International Trade" in H. Kierzkowski (Ed.).) Monopolistic Competition and International Trade. Oxford University Press. Oxford.

Stokey N.L. (1991) "The Volume and Composition of Trade between Rich and Poor Countries". Review of Economic Studies., 58, 63-88.

Torstensson, J. (1996), "Determinants of Intra Industry Trade: A Sensitivity Analysis". Oxford Bulletin of Economics and Statistics, 58(3), 507-524.

White, H. (1980) "A Heteroskedasticity-Consistent Covarience Matrix Estimation and a Direct Test for Heteroskedasticity”, Econometrica, 48, 817-838. 